\title{
El decreto de muerte posterior al tiempo de gracia según Apocalipsis 16:13-14 y 17:12-14
}

\author{
Jorge Daza Michel \\ jorgedazamichel@gmail.com \\ Facultad de Teología \\ Universidad Adventista de Bolivia
}

Recibido: 01 junio de 2017

Aceptado: 08 de julio de 2017

\section{Introducción}

El decreto de muerte es un evento escatológico generalmente ubicado en la narrativa de Apocalipsis 13:15-17, donde se describe el accionar de la imagen de la bestia al perseguir al remanente. Siguiendo la línea tradicional de la teología adventista, dicho acontecimiento se posicionaría en el periodo posgraciano ${ }^{94}$

${ }^{94}$ Esto significa posterior al tiempo del cierre de la gracia. Arthur L. White, "Events Preceding the Second Advent", Review and Herald, octubre 1947, 13. En adelante $R H$; C. J. Ritchie, "The Remnant Church and the Time of Trouble", $R H$, marzo 1950, 8; V. E. Hendershot, "Events Leading to Coming of Christ", $R H$, noviembre 1950, 30; Walter E. Read, "The Great Controversy", en Our Firm Foundation (Hagerstown, MD: Review and Herald Publishing Association, 1953), 2:105-107, 307-310; Ibíd., "The Day of the Lord and the Time of Trouble", $R H$, febrero 1954, 6; Richard B. Lewis, "The Advent Message at Full Tide", $R H$, enero 1959, 9; W. B. Ochs, "Emmanuel...God With Us", $R H$, julio 1962, 20; Fernando Chaij, Preparación para la crisis final (Colombia: Editorial Pacific Press Publishing Association, 1966), 20; Ritchie Way, "The Scope of Prophecy", Ministry, abril 1971, 32; V. A. Fenn, "Waymarks in an Age of Crisis", $R H$, mayo 1971, 5; Robert M. Eldridge, "Gathered "Into a Place"', Ministry, noviembre 1971, 20; Hans K. LaRondelle, "Armagedom" (curso de extensão Andrews IPAE, 1976), 85; Ibíd., Chariots of Salvation (Hagerstown, MD: Pacific Press Publishing Association, 1987), 124-128, 
del marco escatológico. Sin embargo, algunos estudiosos del texto bíblico y de los escritos de Elena G. de White sostienen que el decreto de muerte debe ser ubicado en el periodo pregraciano. ${ }^{95}$

citado en Donald Ernest Mansell, Los adventistas y el Armagedón, trad. David Gullón (Buenos Aires: Asociación Casa Editora Sudamericana, 2006), 107115; "News From Jesus-2", Sabbath School Lesson Quarterly, julio-septiembre, 1974, 67-69; Roy C. Naden, "A Tale of Two Kings", Collegiate Quarterly, enero-marzo, 1987, 119, cf. Richard M. Davidson, "Those Who Are by Wise Shall Understand", Collegiate Quarterly, enero-marzo, 1987, 123; Winston Kent, "The King of North and The Armageddon", Record, octubre 1987, 5; Dan Stevens, "In Quest of the Judgment Event", en Apocalypse Now-II: Study of Book of Revelation, ed. George E. Knowles y Graham Bingham (Nampa, ID: Pacific Press Publishing Association, 1989), 12/3:96; Loron T. Wade, El futuro del mundo revelado en el Apocalipsis (Buenos Aires: Asociación Casa Editora Sudamericana, 1990), 212; Ralph E. Neall, ¿Cuánto aún faltará Señor?, trad. Adriana I. de Femopase (Buenos Aires: Asociación Casa Editora Sudamericana, 1994), 34; Mansell, El perfil de la crisis venidera (Nampa, ID: Pacific Press Publishing Association, 1999), 86; Mario Veloso, Apocalipsis y el fin del mundo: fe para enfrentar la crisis final (Buenos Aires: Asociación Casa Editora Sudamericana, 1999), 205; Máximo Vicuña A., Interpretación histórica del libro de Apocalipsis (Lima: Imprenta Unión, 2000), 129; Norman R. Gulley, "A Song in the night", Ministry, diciembre 1996, 17-19; Ibíd., "Good News About the Time of Trouble", Journal Adventist Theological Studies 7/2 (1996): 126-27. En adelante JATS. Ibíd., "The Good News About Last Day Events", JATS 9/1-2 (1998): 36-7; Ibíd., ;Cristo Viene!: Un enfoque cristocéntrico de los eventos de los últimos días, trad. David Gullón (Buenos Aires: Asociación Casa Editora Sudamericana, 2003), 593; Margaret Sturgill Jeys, The Revelation: A Gift to the Bereans, (n.p., 2005), 1:122, citada en Müller, "Challenges to The Adventist Interpretation of Apocalyptic Literature", Journal Adventist Asia Studies 13/1 (2010): 54. JAAS de aquí en adelante. Mansell, Los adventistas y el Armagedón, 135; Carmelo Martínez, Apocalipsis (Universidad Adventistas del Plata, 2008); Gulley, "Focuson Christ, not the crisis: A discussion on end time events", Ministry, julio-agosto, 2015, 14; Huber Roblero Bravo, "¿Qué es y cuándo termina el tiempo de gracia a la luz de la Biblia y los escritos de Elena G. de White?" (Tesis de Licenciatura, Universidad Montemorelos, 2017), 55.

${ }^{95}$ Anterior al cierre de la puerta de gracia. Ver F. T. Wright, Orden de los eventos finales (Dickendorf: Sabbatruhe-Advent-Gemeinschaft, 2002), 
Ante este desacuerdo, se destacan los estudios que hicieron notar la posible existencia de dos decretos de muerte. El primero, se produciría antes del cierre de la puerta de la gracia, período durante el que parte del remanente sufrirá consecuencias mortales debido a que el martirio forma parte de su obra evangelizadora. El segundo, llegaría posterior al cierre de la puerta de la gracia, época en la que el martirio no tiene lugar, pues la evangelización llegaría a ser innecesaria en aquel tiempo. ${ }^{96}$ Incluso hubo quien

150-57; Gerhard Pfandl, "A Escatologia de Ellen G. White”, en O Futuro: A visão adventista dos últimos acontecimentos, ed. Alberto R. Timm, Amin Rodor y Vanderlei Dornele (Engenheiro Coelho: Unaspress, 2004), 316; Ibíd., El don de profecía: El lugar de Elena G. de White en la iglesia remanente de Dios (Buenos Aires: Asociación Casa Editora Sudamericana, 2008), 82; Ibíd., "Revival and Reformation within the Framework of Last-day Events", Reflections: The BRI Newsletter 34, abril de 2011, 4, cf. Ibíd., Ministry, agosto 2011, 18, 20; Jon Paulien, Armageddon at the Door: An Insider's Guide to the Book of Revelation (Hagerstown, MD: Autumn House, 2008), 179, 175-6; Carlos Olivares, "El decreto de muerte en Apocalipsis y los escritos de Elena G. de White: diferencias y posibles soluciones", Evangelio 7/1 (2014): 119-124, 131-137. Ver también el posible apoyo de esta postura en Ángel Manuel Rodríguez, "Great Apocalyptic Prophecies", Sabbath Schooll Bible Study Guide, abril-junio, 2002, 88-89; Richard Fredericks, "Good News Everybody!", Apocalypse Now-II: Study of Book of Revelation, 49; Kenneth A. Strand, "Apocalyptic prophecy and the church-2", Ministry, diciembre 1983, 16-18; J.R. Spangler, "The Three Angels of the Apocalypse-3: The message of Revelation is the story of the great struggle between Christ and Satan in its ultimate issues", Ministry, julio 1980, 19; LeRoy E. Froom, "Our Purpose in The World", Ministry, noviembre 1933, 21, cf. Idem., "Ideals of Presentation", Ministry (diciembre 1939): 22; Carlyle B. Haynes, Our Times and Their Meaning (Nashville, TN: Southern Publishing Association,1929), 268-69.

${ }^{96} \mathrm{Al}$ parecer, quien propuso en primera instancia una teoría sobre dos decretos de muerte en el Apocalipsis fue Len Tolhurt. A este se le sumó Gerhard Pfandl, al mencionar su propuesta como una posible solución ante aparentes diferencias entre las declaraciones de la Biblia y los escritos de Elena G. de White. Más tarde esta temática se desarrollaría con mayores detalles en un artículo específico escrito por Carlos Olivares. Ver, Len Tohurst, "The Death Dacree in the Setting of the Final Crisis", manuscrito no publicado, 2; G. 
sugirió que esta teoría es capaz de presentar evidencias bíblicas de una advertencia al remanente que atravesaría por estos dos decretos. $^{97}$

Dicho lo anterior, es evidente que la narrativa de Apocalipsis 13:15-17 expresa un decreto de muerte pregraciano. Sin embargo, ninguno de los estudios mencionados anteriormente presenta una porción narrativa del Apocalipsis que describa el segundo decreto propuesto. Por esta razón, el presente estudio intenta responder a la pregunta, ¿existe una o más porciones narrativas del libro de Apocalipsis que describan un decreto de muerte posterior al cierre de la puerta de la gracia?

Para brindar una respuesta sistemática a este cuestionamiento, se analizará primeramente el proceso por el cual se formula el decreto de muerte pregraciano en Apocalipsis 13. Luego, se establecerá el mejor lugar en la narrativa donde pueda ubicarse el decreto de muerte posgraciano y se realizará una comparación estructural y lingüística entre estas secciones, con la finalidad de determinar si es posible proponer una base narrativa para la teoría de ambos decretos en Apocalipsis.

\section{Procedimiento de las bestias para formular el decreto de muerte pregraciano}

Pfandl, "A Escatologia de Ellen G. White", en $O$ Futuro: A visão adventista dos últimos acontecimentos, ed. Amin Rodor, Vanderlei Dorneles y Alberto Timm (Engenheiro Coelho, SP: UNASPRESS, 2004), 316-331; Carlos Olivares, "El decreto de muerte en Apocalipsis y los escritos de Elena G. de White: diferencias y posibles soluciones." Evangelio 7 (2014): 111-137.

${ }^{97}$ Jorge Daza, "El decreto pre y pos graciano en Ap. 13:9-10: un intento de encontrar base bíblica para dicha realidad teológica," Doxa 6 (2016): 7-17. 
La intención constante del dragón en su aparición dentro de la narrativa de Apocalipsis $12^{98}$ es la aniquilación de todos los portadores de bondad divina, tales como el hijo varón, la mujer y el remanente. Dado que este último es el único agente que resta en su lucha (12:17), ${ }^{99}$ en el capítulo 13 puede verse un giro estratégico, pues el dragón comienza a aliarse con dos agentes satánicos para aniquilarlo. ${ }^{100}$ Ambos personajes reciben autoridad sucesiva ${ }^{101}$ y ya

98“"La aparición del dragón contextualiza los capítulos restantes, donde este no solo aparece unido a las bestias $(12: 3,4,7,9,13,16,17 ; 13: 2,4,11 ; 16: 13$; 20:2), sino que también sirve de vínculo con la descripción de la bestia de Apocalipsis 13:1 y 17:3." Ver Carlos Olivares, "Análisis estructural de Apocalipsis 12 y 13: En busca de un esqueleto estructural”, Theologika 20 (2005): 36. En adelante Theo.

99،"El contexto de Apocalipsis 13 es una ampliación del ataque del dragón al pueblo remanente presentado en 12:17; es decir, el versículo 17 es un resumen de la guerra entre el dragón y el remanente que se desarrolla en detalle en los capítulos 13 y 14." Jon Paulien, "Revisiting the Sabbath in the Book of Revelation", Journal of the Adventist Theological Society 9/1 (1998): 182, citado en, Fernando Rojas, "¿Es Estados Unidos la segunda bestia de Apocalipsis 13:11-17? Parte I", Didajé 1/1 (2012): 114.

${ }^{100}$ Mueller al describir el ataque de Satanás contra el remanente declara: "También usa la bestia que viene del mar y la bestia que sale de la tierra en su intento de aniquilarlo [al remanente]". Ekkehardt Mueller, "La universalidad de la iglesia en el Nuevo Testamento", en Mensaje, Misión y Unidad de la Iglesia, ed. Ángel M. Rodríguez (Buenos Aires, Argentina: Asociación Casa Editora Sudamericana, 2015), 31.

${ }^{101}$ Teniendo como fundamento la estructura completa de la persecución del dragón (12:1-13:18), existe un orden de aparición y delegación de autoridad. El dragón (12:3) delega su "autoridad" a la bestia que surge del mar $(13: 2 b, 4)$, y esta, a su vez, se la delega a la bestia que sube de la tierra (13:12). En el primer caso, que describe la facultad delegada de autoridad entre el dragón y la bestia marítima, es preciso observar el traspaso de las diademas. Mientras que en el capítulo 12 las diademas están sobre sus cabezas (12:3), en el capítulo 13 la bestia las tiene sobre sus cuernos (13:1). A diferencia de la bestia de Apocalipsis 17 que no tiene ninguna (17:3). Las diademas, entre los griegos y romanos, representaban la marca distintiva de realeza u honor, por lo cual su 
no presentan intenciones directas de aniquilación, ${ }^{102}$ sino que proporcionan la plataforma para un decreto de muerte formulado por la imagen de la bestia y llevado a cabo por los moradores de la tierra, quienes se convierten en el agente activo del dragón, puesto que la imagen de la bestia no mata sino que hace "matar a todo el que no la adorase" (13:15). ${ }^{103}$

De esta manera la trinidad satánica, "engaña"104 a los moradores de la tierra y los convierte en su principal agente de aniquilación. Así es como reciben la marca de la bestia, pues se han

posición, en el contexto del libro, simbolizaría el gobierno del dragón y la bestia (cf. 19:12). Ver Henry George Liddell y Robert Scott, A Greek-English

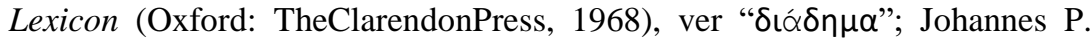
Louw y Eugene A. Nida, eds., Greek-English lexicon of the New Testament based on Semantic Domains (Nueva York: UnitedBibleSocieties, 1989), ver

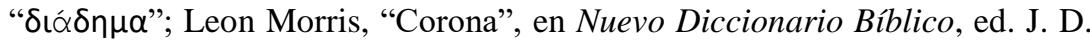
Douglas (Barcelona: Certeza, 1991), 288-289, citado en Olivares, "Análisis estructural de Apocalipsis 12 y 13", 54.

${ }^{102}$ En palabras de Olivares "se nos dice que la bestia es sanada de una herida que parecía fatal, lo cual ocasiona la admiración y adoración de 'toda la tierra' (13:3-4). Esto pareciera indicar que la bestia es presentada como un personaje pasivo, el cual si bien es descrito recibiendo autoridad (13:2), se omite cualquier referencia a sus actividades". Por ejemplo, aunque el dragón le "da" poder y autoridad a la bestia, no se dice nada en relación al ejercicio de ese poder (13:2). Ver Olivares, "Blasfemias contra el santuario celestial: un análisis literario de Apocalipsis 13:6", Evangelio 8 (2015): 16.

103،'La frase 'decreto de muerte' es una expresión técnica comúnmente utilizada por autores adventistas para describir la persecución mundial llevada a cabo por los creyentes infieles contra los verdaderos adoradores de Dios en el tiempo del fin". Arthur S. Maxwell, "New Year's Dawn," Sign of the Times, 5 de enero de 1953, 2; énfasis añadido. Beatrice S. Neall, "No Need toWorry: Good News about the Dinal Conflict", Adventist Review, Junio 1995, 13; Marvin Moore, Challenges to the remnant: Adventists, Catholics and the "True church" (Nampa: Pacific Press, 2008), 229-230, citado en Olivares, "El decreto de muerte en Apocalipsis", 111.

${ }^{104}$ Treiyer, al realizar un quiasmo de Apocalipsis 13:11-15, identifica que el "engaño" es la principal acción de la bestia terrestre. Ver Enrique Treiyer, 
vuelto aliados ${ }^{105}$ del dragón en la lucha contra el remanente. ${ }^{106}$ Dicho engaño se compone de dos acciones similares que maravillan a los moradores de la tierra. La primera, se registra en Apocalipsis 13:3-4, donde la bestia que sube del mar imita el sacrificio de Cristo y su resurrección (13:3) ${ }^{107}$ luego de haber recibido el poder, el trono y grande autoridad de parte del dragón (13:2). Entonces los moradores de la tierra adoran al dragón y a la bestia

"Ap 13:11-18: feu du Ciel et Marque de la Bete", Andrews University Seminary Studies 37/1 (1999): 73-86. En adelante AUSS.

${ }^{105}$ Para Jon K. Paulien los libros apocalípticos "presentan al mundo malvado y opresor bajo el aparente control de Satanás y de sus cómplices humanos". Ver Paulien, "La hermenéutica de la apocalíptica bíblica", en Entender las sagradas escrituras, ed. George Reid (Buenos Aires, Argentina: Asociación Casa Editora Sudamericana, 2010) 302. Énfasis añadido.

${ }^{106}$ Desde esta perspectiva es evidente que la marca no es recibida en su totalidad al adorar a la imagen, sino cuando los moradores de la tierra acatan el decreto de muerte y lo ejecutan. Fernando Rojas pareciera apoyar esta idea al decir que "una vez que se les ha puesto la marca o la señal, forman parte del dragón, la bestia marítima y la bestia terrestre, porque el texto dice que la marca consiste en llevar 'el nombre de la bestia y el número de su nombre' (v. 17)", 127. Énfasis añadido.

107 “Es interesante que el verbo utilizado por Juan para describir la escena de la 'herida mortal' de esta bestia es el mismo que usa para referirse al 'degüello' sufrido por Cristo (5:6). De esta manera, literalmente el texto señala que una de sus cabezas está 'como degollada' (13:3), imitando la muerte expiatoria de Cristo en la cruz. Pero, así como en el caso de Cristo, esta 'herida mortal' milagrosamente es sanada (13:3), provocando la admiración y adoración de la tierra (13:3-4, 8; cf.17:8). En pocas palabras, la bestia resucita suscitando el mismo asombro y adoración de la corte celestial por la inmolación y resurrección del Cordero (5:9)". Louis Were, The Woman and the Beast in the Book of Revelation (Berrien Spring, MI: First Impression, 1983), 56-57; Pablo Richard, Apocalipsis: Reconstrucción de la Esperanza (Caracas: San Pablo, 2001), 151, citado en Olivares, "Parodia trinitaria en el Apocalipsis", Advenimiento 2 (2005): 62. 
diciendo “¿Quién como la bestia?” (13:4), emulando así el nombre de Jesucristo. ${ }^{108}$

La segunda acción se registra en Apocalipsis 13:11-14, donde la bestia que surge de la tierra realiza grandes señales y hace descender fuego del cielo, ${ }^{109}$ ejerciendo la autoridad del dragón y la bestia marítima, y promocionando la adoración de la primera bestia cuya herida de muerte fue sanada. ${ }^{110}$ Ambas acciones engañan a los moradores de la tierra y los incitan a formar una imagen, la cual ordena matar a quienes no la adorasen.

108،... los habitantes de la tierra preguntan, engañados, ‘¿quién como la bestia?' (13:4), lo que simula el significado del nombre de Miguel, que es uno de los nombres recibidos por Jesucristo (12:7, cf. Dn 10:13, 21; 12:1; Jud 9), el cual también como una interrogación significa "¿quién es como Dios?". Seventh-day Adventist Bible Dictionary, ed. rev., 1978, ver "Michael"; Jacques Doukhan, Secrets of Revelation: The Apocalypse through Hebrew eyes (Hagerstown, MD: Review and Herald, 2002), 114-115; C. C. Martindale, "Apocalipsis", en Verbum Dei, comentario a las Sagradas Escrituras, ed. B. Orchard et al. (Barcelona: Herder, 1959), 482; Olivares, "Parodia trinitaria", 62-63.

${ }^{109}$ Considerados como una parodia de la parusía. Ver Jon Paulien, What the Bible Says About the End-Time (Hagerstown: Review and Herald, 1994), 112; Ángel Manuel Rodríguez, Fulgores De Gloria (Buenos Aires: Asociación Casa Editora Sudamericana, 2001), 123. Por otro lado, es probable que Cottrell, tácitamente, esté señalando lo mismo al referirse al engaño final en el que el diablo se hace pasar por Jesús según 2 Tesalonicenses 2:9 y Apocalipsis 13:13. Ver Roy Cottrell, "Healing, Counterfeit and Genuine", Review and Herald, 9 de junio 1949, 11. Una idea similar se percibe en Kenneth Wood, quien, señalando la impostura del diablo, afirma que el espiritismo jugará un importante rol en los eventos finales; ver K. H. Wood, "Espiritism", Review and Herald, 19 de febrero de 1959, 3. Ver también Ángel Manuel Rodríguez, "Grandes profecías apocalípticas", en Guía de Estudio de la Biblia, ed. para maestros (Buenos Aires: Asociación Casa Editora Sudamericana, abril-junio 2002), 124, citado en Olivares, "El fuego del cielo (Ap 13:13) y la falsa parusía: Una mirada desde los escritos de Elena G. de White y la Biblia", Evangelio 6 (2013): 136, 141-143.

110،... el objetivo de ambas investiduras de poder es recibir la adoración y la lealtad de toda la humanidad (Dn 7:14, 27; Ap 13:4)", LaRondelle, Las profecias del fin, 299. 
En resumen, el decreto de muerte en Apocalipsis es el resultado de un engaño satánico con dos acciones estratégicas que poseen el mismo procedimiento en sus elementos. Ambas se inician con una recepción de autoridad (13:2; cf. 13:11-12) y realizan una parodia satánica (13:3-4; cf. 13:13). En consecuencia, ambas participaciones reciben la adoración de cómplices humanos (13:4; cf. 13:14), quienes se unen en el propósito de aniquilar al remanente (13:7; cf. 13:15) como puede verse en el siguiente cuadro:

\begin{tabular}{|l|l|}
\hline $\begin{array}{c}\text { Primera acción de engaño } \\
\text { Ap13:2-7 }\end{array}$ & \multicolumn{1}{|c|}{$\begin{array}{c}\text { Segunda acción de engaño } \\
\text { Ap13:11-15 }\end{array}$} \\
\hline Recepción de autoridad & Recepción de autoridad \\
\hline Parodia satánica & Parodia satánica \\
\hline $\begin{array}{l}\text { Participación de cómplices } \\
\text { humanos }\end{array}$ & $\begin{array}{l}\text { Participación de cómplices huma- } \\
\text { nos }\end{array}$ \\
\hline $\begin{array}{l}\text { Propósito: aniquilación del re- } \\
\text { manente }\end{array}$ & $\begin{array}{l}\text { Propósito: aniquilación del rema- } \\
\text { nente }\end{array}$ \\
\hline
\end{tabular}

Tabla 1. Similitudes entre las dos acciones de engaño de satanás

Se debe tomar en cuenta que el decreto de muerte posgraciano es llevado a cabo después de que la puerta de la gracia se haya cerrado, lo cual implica que su ejecución ya no tendría efecto mortal sobre el remanente. La sangre de mártires para ese futuro no tendría razón de ser, pues toda predicación en aquel período sería vana. Por otro lado, al cerrarse la puerta de gracia, la paciencia de Dios terminó 
y se inicia la venganza divina a través de las plagas. Bajo esta perspectiva, la porción bíblica del libro de Apocalipsis que exprese un posible decreto de muerte posgraciano debería ubicarse en el septenario de las plagas.

La narrativa de las plagas se inicia indicando que existen dos grupos definidos. El primero es el grupo de los victoriosos, cuya victoria fue sobre la bestia y su imagen (Ap 15:2). Ellos expresan el mismo cántico de victoria que los 144.000 (15:3; cf. 14:3), pero se diferencian de ellos por el mensaje que proclaman, ya que los 144.000 emiten un mensaje de advertencia ante la marca de la bestia y su imagen (14:6-11), mientras que los victoriosos de Apocalipsis 15 emiten un mensaje de alabanza y gloria a Dios por la victoria obtenida sobre la marca de la bestia y su imagen (15:4).

Esto indicaría que, para ese entonces, no existirá más necesidad de un mensaje de advertencia, pues la puerta de gracia se ha cerrado. ${ }^{111} \mathrm{La}$ ira de Dios se ha desatado y siete ángeles están prestos a derramar las plagas de sus copas sobre el grupo de impíos, quienes tienen la marca de la bestia y adoran a su imagen (16:2). De aquí en adelante, se narra una serie de acontecimientos futuros posteriores al fin del tiempo de gracia, los cuales concluyen con la victoria de Cristo contra el mal. Esta batalla se inicia con el último intento satánico por alcanzar la victoria cósmica junto a los tres agentes satánicos que poseen forma de ranas

${ }^{111}$ Para un análisis más detallado de la posición bíblica sobre el cierre de la puerta de gracia en el inicio de las plagas, ver Hans K. LaRondelle, Las profecías del fin, trad. David P. Gullón (Buenos Aires: Asociación Casa Editora Sudamericana, 1999), 172-74; Marvin Moore, Los desafíos del remanente, trad. Ana Laura Gálvez Cruz, 2da ed. (Mexico, D.F.: Gema Editores, 2010), 253-55; Ranko Stefanovic, La revelación de Jesucristo: Comentario del libro de Apocalipsis (Berrien Springs: Andrews University Press, 2013), 470-71. 
(16:13-14), ${ }^{112}$ una clara alusión al último permiso de Dios para que el mal muestre su parodia, tal como sucedió en Egipto (Ex 78). ${ }^{113}$

\section{Análisis comparativo de Apocalipsis 13 y 16}

Así pues, se podría elegir la sección de Apocalipsis 16:1314 como la posible expresión de un decreto de muerte posgraciano, ${ }^{114}$ con la finalidad de realizar una comparación de este engaño con los antecedentes diabólicos mostrados en Apocalipsis 13. Encontrar un paralelo entre las actuaciones del enemigo en Apocalipsis 13 y 16 proporcionarían no solo el sustento teoló-

${ }^{112}$ Mueller, en un artículo referido a la persecución de los creyentes, afirma que "la batalla del Armagedon $(16: 14,16)$ será el enfrentamiento final en el tiempo histórico". Ver Mueller, "Revelation`s Perspective on Persecution", Adventist Research Institute, https://www.adventisttbiblicalresearch.org/materials/practical-christian-living/revelations-perspective-persecution (consultado: 10 de enero de 2017).

${ }^{113}$ Paulien, Armageddon at the Door, 89.

${ }^{114}$ Se puede decir que las intenciones de persecución no han cedido aun en Apocalipsis 16, puesto que su narrativa "clasifica a Ap. 16 como el juicio venidero contra una Babilonia mundial que está en rebelión contra Dios y en guerra contra sus santos (16:1,5-6)". Ver Hans K. LaRondelle, "Aproximación contextual a las siete plagas postreras", en Simposio sobre Apocalipsis II, ed. Frank B. Holbrook (Florida: Asociación Publicadora Interamericana, 2011), 182. Énfasis añadido. "Los que están de pie en el mar de vidrio están venciendo... a la bestia y su imagen, no han vencido. Siguen implicados en la lucha contra la bestia mientras están de pie en el mar de vidrio", Beatrice Neall, "Los santos sellados y la tribulación", Simposio sobre Apocalipsis I, ed. Frank B. Holbrook (Frorida: Asociación Publicadora Interamericana, 2010), 321. El énfasis está en el original. 
gico para evidenciar la existencia de los decretos pre y posgracianos, sino también una plataforma narrativa para ubicar el decreto de muerte posgraciano. ${ }^{115}$

\section{Recepción de autoridad y parodia satánica}

Para iniciar este paralelo comparativo, la sección de Apocalipsis 16:13-14 debe presentar una recepción de autoridad similar a la de Apocalipsis 13:2 y 13:11-12. El texto bíblico registra "y vi salir de la boca del dragón, y de la boca de la bestia, y de la boca del falso profeta, tres espíritus inmundos a manera de ranas" (16:13, R60). Debe notarse que la expresión sto,ma (stóma, 'boca') es enfática. El primer agente satánico mencionado en el versículo es el dragón, quien anteriormente utiliza su boca para arrojar un río tras la mujer a fin de arrastrarla (12:15). Considerando la imagen de conjunto, ${ }^{116}$ esta escena pareciera ser la acción seminal del dra-

${ }^{115}$ Hay quienes aplican la narrativa de Apocalipsis 16:13-14 como una expresión mimetizada del actuar del trio satánico de Apocalipsis 13:11-18 en oposición al triple mensaje angélico de Apocalipsis 14:6-13. Ver, por ejemplo, LaRondelle, "O Armagedom na perspectiva bíblica", en $O$ Futuro: A visão adventista dos últimos acontecimentos, 177-88; Paulien, Armageddon At the Door, 151-68. Sin embargo, esta visión daría a entender implícitamente que el actuar satánico de Apocalipsis 16:13-14 es parte de la persecución (decreto de muerte), previa al cierre de la puerta de gracia, condensando los períodos pre y posgracianos. El presente estudio acepta la similitud entre la narrativa de Apocalipsis 13 y 16, pero se inclina a diferenciarlas, puesto que el mismo texto parece mostrar esta división natural. De igual modo, Treiyer parece apoyar la idea de una segunda actuación y no una condensación de ambas en "Fuego del cielo y marca de la bestia: Un estudio exegético de Apocalipsis 13: 11-18”, 8182. No obstante, el problema es aún debatible.

${ }^{116}$ Jon Paulien recomienda, "Centrarse en la lectura secuencial. Conviene pasar la mayor parte del tiempo dedicado al estudio leyendo la Biblia y no buscando cosas con una concordancia. Cuando se leen los libros bíblicos de principio a fin, el autor bíblico tiene el control del orden y del flujo del material. Por lo tanto, la lectura frecuente de la Biblia en porciones grandes afianza al 
gón, en la que él mismo otorga su autoridad a otro agente para cumplir sus propósitos diabólicos. En consecuencia, la expresión sto,ma (stóma) 'boca' podría ser un homónimo de autoridad en el lenguaje apocalíptico.

Posteriormente, la bestia, el segundo agente presente en Apocalipsis 16:13, correspondería a la bestia marítima en vista de la sucesión narrativa de los capítulos 12 y 13. Esta posee un antecedente textual en Apocalipsis 13:5, donde se puede encontrar un paralelo literario entre la expresión boca (stóma) y autoridad, pues el versículo expresa: "Se le dio una boca que hablaba palabras arrogantes y blasfemias; y se le dio autoridad para actuar durante cuarenta y dos meses".

La repetición de la expresión "se le dio", que en griego es idéntica, podría evocar una base textual para establecer un paralelo entre ambos sintagmas. De esta forma, el segundo sintagma llegaría a ser la base aclaratoria del primero, es decir, la boca representaría la autoridad otorgada y las blasfemias durarían un periodo de cuarenta y dos meses. Nuevamente, aquí la boca llegaría a ser un homónimo de autoridad. ${ }^{117}$

Y por último, el falso profeta o bestia terrestre, si bien no tiene relación directa con el término boca (sto,ma, stóma) en otra sección de Apocalipsis, es posible adjudicarle un paralelo con la expresión lale,w (laleo) 'habla como dragón' (13:11). Obviamente, los términos lengua (laleo) y boca (stóma) no son iguales, pero sí poseen relación semántica. Lo destacable es que en la narrativa el

intérprete en las intenciones de los autores originales. Por otra parte, cuando usamos una concordancia controlamos dónde vamos y lo que aprendemos. Aunque el estudio con concordancia es un instrumento valioso, hay peligro de que los árboles no nos dejen ver el bosque. La lectura secuencial de la Biblia mantiene nuestros ojos atentos a la imagen de conjunto". Ver Paulien, "La hermenéutica de la apocalíptica bíblica", 309. El énfasis está en el original.

${ }^{117}$ Otra argumentación de un paralelo entre hablar y la autoridad en términos estructurales lo proporciona Olivares, "Análisis estructural de Apocalipsis 12 y 13 ", 50-51. 
hablar de la bestia se relaciona con la autoridad, pues el falso profeta "habla como dragón y ejerce toda la autoridad de la primera bestia" (13:11-12). La conjunción y con la que se inicia el versículo 12 podría establecer una relación explicativa. Visto de esta manera, el hecho de "hablar como dragón" llegaría a ser la acción de ejercer autoridad.

Por consiguiente, el hecho de presentar a los tres agentes satánicos de Apocalipsis 12 y 13 juntos con un mismo propósito (16:13) lanzando de sus bocas tres agentes para que lo cumplan muestra claramente que, en esta escena, toda su autoridad converge para ejecutar la última acción satánica de imitación. Dicha acción se traduce en el segundo requisito paralelo de esta comparación, pues los espíritus son a manera de ranas y el milagro de las ranas en Egipto fue el último prodigio que pudieron imitar los hechiceros del Faraón. De esta manera, el mensaje paródico de los tres ángeles ${ }^{118}$ llegaría a reactivarse en esta escena. Adicionalmente, es importante notar que los espíritus realizan señales (16:14), término idéntico al de Apocalipsis 13:13-14. Esto podría dar a entender que existe una contestación de la primera parodia satánica (13:14-15) en la sección de Apocalipsis 16:13-14. ${ }^{119}$

\section{Cómplices humanos y aniquilación del remanente}

Además de esto, los espíritus inmundos se dirigen a reunir cómplices humanos (los reyes de la tierra), quienes engañados por los mismos aceptan el mensaje satánico. Este mensaje opuesto al mensaje de los tres ángeles los conduce a una batalla. De esto se

${ }^{118}$ Los tres espíritus a manera de ranas de Apocalipsis16:13-14, de acuerdo a un análisis paródico, pueden ser una imitación satánica del mensaje de los tres ángeles de Apocalipsis 14:6-14. Véase, Paulien, What the Bible Says About the End-Time, 114; Rodríguez, Fulgores De Gloria, 134; Olivares, "Parodia trinitaria", 66.

${ }^{119}$ LaRondelle, refiriéndose a la actividad de la bestia terrestre, declara que "su actividad significa el comienzo del acto final en el drama de los siglos que conduce al último enfrentamiento entre Cristo y Satanas: 'el Armagedon"”, Las profecías del fin, 313 . 
podría deducir que la principal intención o propósito en esta escena es la aniquilación de todo agente de bondad, es decir, de Cristo y los victoriosos. Esta narración, a diferencia de todo el contexto anterior a las plagas (12-14), no expone la muerte ni el martirio del remanente, pues la batalla solo es mencionada y no expresa resultados ni consecuencias mortales como en Apocalipsis13:7, donde los santos son vencidos, o Apocalipsis 14:12-13, donde la muerte del remanente se traduce en bienaventuranza.

\section{Análisis comparativo de Apocalipsis 16 y 17}

Quizá el fin de la batalla incitada por estos tres espíritus inmundos a manera de ranas encuentra su realización en Apocalipsis 17:12-14 ${ }^{120}$, dado que allí se presentan elementos similares a Apocalipsis 16:13-14. "' "Y los diez cuernos que has visto, son diez reyes, que aún no han recibido reino; pero por una hora recibirán autoridad como reyes juntamente con la bestia. Éstos tienen un mismo propósito, y entregarán su poder y su autoridad a la bestia. Pelearán contra el Cordero, y el Cordero los vencerá, porque Él es Señor de señores y Rey de reyes; y los que están con Él son llamados y elegidos y fieles" (17:12-14, R60).

Ambas escenas presentan una recepción de autoridad. La primera, con la boca de los tres agentes satánicos (16:13); la segunda, con la autoridad conferida a los reyes (17:12). Los aliados humanos también son los mismos, porque son reyes. Asimismo, las dos escenas presentan una alianza, pues de la boca de los tres agentes salen ranas, seres de una misma especie, mientras que la segunda escena menciona que los reyes y la bestia tienen un mismo propósito (17:13). Ambas presentan un propósito de

\footnotetext{
${ }^{120}$ LaRondelle, “Aproximación contextual a las siete plagas postreras”, 185.

${ }^{121}$ Para LaRondelle, no solo existe similitudes en ambos capítulos, sino que los capítulos 16 y 17 son una unidad estructural y temática, Ibíd., 184
} 
aniquilación pues Apocalipsis 16:14 menciona una batalla y Apocalipsis 17:14 declara que pelearán, aludiendo implícitamente a la misma batalla. Este paralelo se puede ver en el siguiente cuadro, salvo el desenlace final que presenta Apocalipsis 17:14, pues allí el Cordero junto con el remanente vence en la última batalla.

\begin{tabular}{|l|l|}
\hline \multicolumn{1}{|c|}{ Apocalipsis 16:13-14 } & \multicolumn{1}{c|}{ Apocalipsis 17:12-14 } \\
\hline Recepción de autoridad & Recepción de autoridad \\
\hline Reyes & Reyes \\
\hline Alianza & Alianza \\
\hline Propósito de aniquilación & Propósito de aniquilación \\
\hline & $\begin{array}{l}\text { Victoria final del Cristo y el re- } \\
\text { manente }\end{array}$ \\
\hline
\end{tabular}

Tabla 2: Similitudes entre Apocalipsis 16: 13-14 y 17: 12-14

\section{Conclusión}

Extrapolando todas las narraciones que se han analizado previamente, se podría decir que la actuación de los agentes satánicos junto con sus aliados humanos tiene como propósito la aniquilación del remanente, el cual se manifiesta en un decreto de muerte expresado primeramente en el capítulo 13, que tiene ecos linguísticos y temáticos en Apocalipsis 16:13-14 y 17:12-14. Ambas narraciones están ubicadas en el momento anterior a la venida de Cristo, justo cuando las plagas están cayendo sobre la tierra, pues la puerta de gracia ya está cerrada. Esta comparación narrativa puede verse en sus paralelos temáticos dentro del siguiente cuadro. 


\begin{tabular}{|c|c|c|c|}
\hline \multicolumn{2}{|c|}{ Tiempo pregraciano } & \multicolumn{2}{|c|}{ Tiempo posgraciano } \\
\hline Ap 13:2-7 & Ap 13:11-15 & Ap 16:13-14 & Ap 17:12-14 \\
\hline $\begin{array}{l}\text { Recepción de } \\
\text { autoridad }\end{array}$ & $\begin{array}{l}\text { Recepción de } \\
\text { autoridad }\end{array}$ & $\begin{array}{l}\text { Recepción de } \\
\text { autoridad }\end{array}$ & $\begin{array}{l}\text { Recepción de } \\
\text { autoridad }\end{array}$ \\
\hline $\begin{array}{l}\text { Parodia satá- } \\
\text { nica }\end{array}$ & $\begin{array}{l}\text { Parodia satá- } \\
\text { nica }\end{array}$ & $\begin{array}{l}\text { Parodia satá- } \\
\text { nica }\end{array}$ & Alianza \\
\hline $\begin{array}{l}\text { cómplices hu- } \\
\text { manos }\end{array}$ & $\begin{array}{l}\text { cómplices hu- } \\
\text { manos }\end{array}$ & $\begin{array}{l}\text { cómplices hu- } \\
\text { manos }\end{array}$ & $\begin{array}{l}\text { cómplices hu- } \\
\text { manos }\end{array}$ \\
\hline $\begin{array}{l}\text { Propósito: ani- } \\
\text { quilación del } \\
\text { remanente }\end{array}$ & $\begin{array}{l}\text { Propósito: } \\
\text { aniquilación } \\
\text { del remanente }\end{array}$ & $\begin{array}{l}\text { Propósito de } \\
\text { aniquilación }\end{array}$ & $\begin{array}{l}\text { Propósito de } \\
\text { aniquilación }\end{array}$ \\
\hline $\begin{array}{l}\text { Victoria de la } \\
\text { bestia sobre los } \\
\text { santos }\end{array}$ & & & $\begin{array}{l}\text { Victoria final } \\
\text { del Cristo y el } \\
\text { remanente }\end{array}$ \\
\hline
\end{tabular}

Tabla 3: Comparación entre el tiempo pregraciano y el posgraciano

Por consiguiente, se puede afirmar que la realidad teológica acerca de dos decretos de muerte - uno previo al cierre de la puerta de la gracia y otro posterior a este - llamados decretos pre y posgraciano se hacen tangibles en el Apocalipsis. Y, de acuerdo al objetivo del presente estudio, se concluye que la teoría sobre un decreto de muerte posgraciano halla base bíblica en los textos 
de Apocalipsis16:13-14 y 17:12-14, puesto que poseen las mismas características, en procedimiento y narración, que Apocalipsis 13 , donde se expresa el decreto de muerte pregraciano. 